\title{
EVALUATION OF THE RESULTS FROM REOPERATIONS ON PATIENTS WITH ROTATOR CUFF LESIONS
}

Alberto Naoki Miyazaki ${ }^{1}$, Marcelo Fregoneze ${ }^{2}$, Pedro Doneux Santos ${ }^{3}$, Luciana Andrade da Silva ${ }^{3}$, Guilherme do Val Sella ${ }^{3}$, Ruy Mesquita Maranhão Santos ${ }^{4}$, Adriano de Souza ${ }^{4}$, José Renato Depari Estelles ${ }^{5}$, Sérgio Luiz Checchia ${ }^{6}$

\section{ABSTRACT}

Objectives: To assess the results from open or arthroscopic surgical treatment on patients with symptomatic recurrence of rotator cuff injuries. Methods: Between December 1990 and July 2007, 30 patients were assessed and underwent reoperation performed by the Shoulder and Elbow Surgery Group of the Department of Orthopedics and Traumatology, Fernandinho Simonsen Wing, Santa Casa de São Paulo, because of dehiscence of the rotator cuff suture. The study included patients with symptomatic recurrence of the injury and with at least 24 months of postoperative follow-up. Results: According to the UCLA evaluation criteria, 21 patients
$(70 \%)$ showed excellent or good outcomes; and nine patients $(30 \%)$ showed fair or poor outcomes. Conclusion: Open or arthroscopic surgical treatment of recurrent rotator cuff injuries tended to present worse results than from the primary repair. In this study, we found that $70 \%$ of the results were excellent and good. The presence of extensive injuries in the reoperation tended to evolve with larger numbers of unsatisfactory results. In our study, we obtained better results from arthroscopic surgery than from open surgery.

Keywords - Shoulder; Rotator Cuff/injuries; Arthroscopy; $\neg$ Reoperation

\section{INTRODUCTION}

Complete injuries of the rotator cuff give rise to significant pain and functional deficit, and surgical treatment may be indicated ${ }^{(1)}$. However, surgical treatment is not always successful: failure or lesion recurrence may occur ${ }^{(1)}$. Magnetic resonance imaging studies have demonstrated that the recurrence rates after open repair on large and extensive lesions are between 10 and $86 \%$, while for arthroscopic repair, between 31 and $94 \%$ of patients represent recurrence, among whom most cases are asymptomatic ${ }^{(2-4)}$.

Poor clinical results have been reported in up to $25 \%$ of the cases repaired ${ }^{(5-7)}$, and the following factors may be associated with such occurrences: presence of large and extensive lesions, quality of the tendon to be sutured, fatty degeneration of the muscle, surgical technique used, surgical damage caused to the origin of the deltoid muscle and inadequate postoperative rehabilitation $^{(1,8-10)}$.

There is little information in the literature on

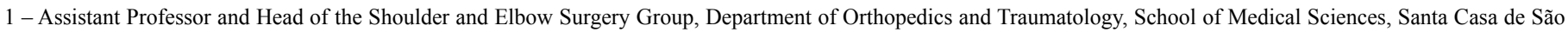
Paulo, São Paulo, Brazil.

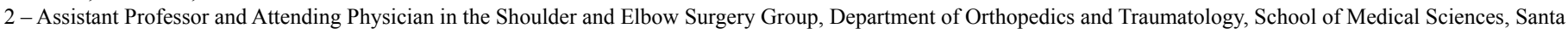
Casa de São Paulo, São Paulo, Brazil.

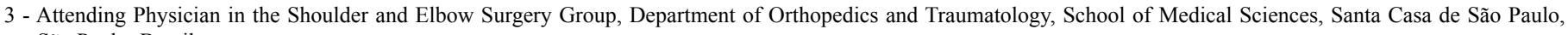
São Paulo, Brazil.

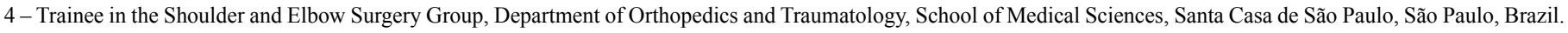

5 - Undergraduate Student at the School of Medical Sciences, Santa Casa de São Paulo, São Paulo, Brazil.

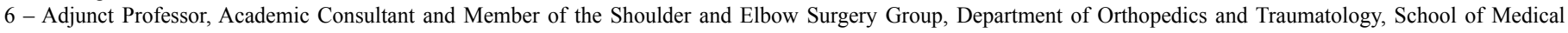
Sciences, Santa Casa de São Paulo, São Paulo, Brazil.


Brazil. Director: Prof. Dr. Osmar Avanzi.

Correspondence: R. Dr. Cesário Mota Jr 112 - Vila Buarque - 01221-020 - São Paulo, SP. E-mail: ombro@ombro.med.br

Work received for publication: February 17, 2010; accepted for publication: August 20, 2010 
asessments of reoperated cases and their long-term evolution. These are situations that are difficult to resolve, and the results are generally inferior to the primary repair, given that although pain relief may be achieved, improvement of limb function is less likely ${ }^{(1,5,9,11)}$. DeOrio and Cofield ${ }^{(12)}$ reported that $58 \%$ of the results from attempted second repair of lesions using an open approach were poor, with little pain relief or improvement of mobility. Neviaser and Neviaser ${ }^{(5)}$ reported an improvement of pain in $92 \%$ of the cases reoperated via an open approach, with an increase in mean elevation from $92^{\circ}$ to $137^{\circ}$. Ma et al $l^{(6)}$ found that $55 \%$ of the results from second repair using open surgery were satisfactory; Lo and Burkhart ${ }^{(11)}$ obtained four excellent and five good results (64\% satisfactory) out of 14 patients who underwent a new surgical procedure using an arthroscopic route.

The aim of this study was to clinically and functionally assess patients with recurrence of rotator cuff lesions who underwent a new surgical procedure by means of either an open or an arthroscopic approach.

\section{SAMPLE AND METHODS}

Between December 1990 and July 2007, the Shoulder and Elbow Surgery Group of the Department of Orthopedics and Traumatology of Santa Casa de São Paulo, Fernandinho Simonsen Wing, surgically treated 30 patients (30 shoulders) who presented symptomatic recurrence of rotator cuff lesions.

The inclusion criteria were that these were cases that were operated using either an open or an ar-
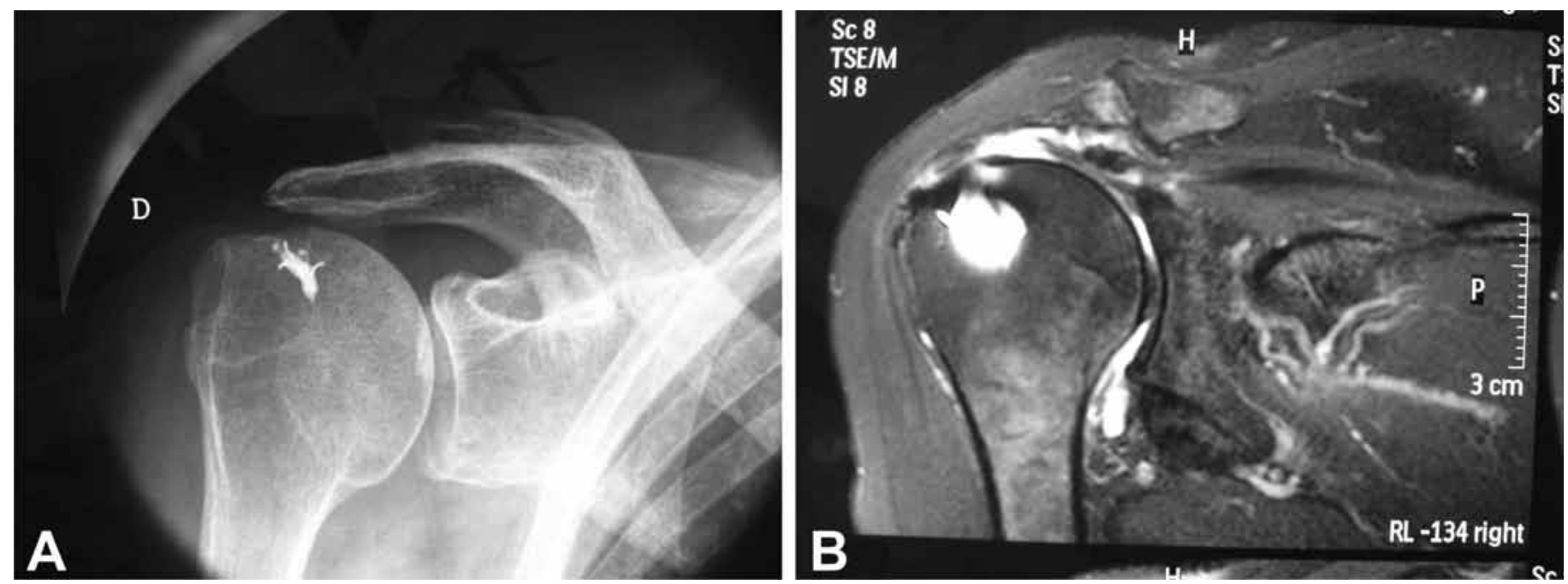

Figure 1 - Example of radiograph $(A)$ and magnetic resonance image $(B)$ of the right shoulder, showing tear in the tendon of the spinal supraspinatus muscle.

Rev Bras Ortop. 2011;46(1):45-50 
another service were unable to give precise information regarding the time when their symptoms returned. Histories of trauma were associated with symptom recurrence in 10 patients $(33.3 \%)$ and of these, seven $(70 \%)$ reported falls to the ground and three (30\%) reported having made unusually large physical effort. The time interval between the first surgery and the revision was on average 27 months, with a range from one to 230 months (Table 1).

An open surgical access route was used for 11 patients (36.6\%), while arthroscopic surgery was used for 19 patients (63.4\%) (Table 1). All the patients underwent their operations in the "deckchair" position, under general anesthesia in association with anesthetic block of the brachial plexus.

In the cases that were operated using an open route, we used an anterior deltopectoral access. In 10 of these cases $(90.9 \%)$, the lesion was repaired using transosseous stitches, while one case underwent fixation using anchors $(9.1 \%)$. In the cases treated arthroscopically, anterior, posterior and lateral portals were constructed, with accessory portals when necessary for repairing the lesion using anchors (Table 1).

With regard to the sizes of the lesions at the time

Table 1 - Clinical data on the patients.

\begin{tabular}{|c|c|c|c|c|c|c|c|c|c|c|}
\hline Patient & Age & Sex & Dominance & $\begin{array}{l}\text { Time between } 1^{\text {st }} \text { and } 2^{\text {nd }} \\
\text { operations (months) }\end{array}$ & $\begin{array}{l}\text { Lesion size in } \\
\text { reoperation }\end{array}$ & $\begin{array}{c}\text { Surgery } \\
\text { type }\end{array}$ & $\begin{array}{c}\text { No. of } \\
\text { anchors }\end{array}$ & $\begin{array}{l}\text { Follow-up } \\
\text { (months) }\end{array}$ & UCLA & Complications \\
\hline 1 & 55 & $\mathrm{~F}$ & + & 36 & Medium & Open & * & 152 & 24 & \\
\hline 2 & 61 & $M$ & + & 8 & Medium & Video & 1 & 130 & 35 & \\
\hline 3 & 70 & $M$ & + & 11 & Large & Open & * & 38 & 15 & \\
\hline 4 & 60 & $M$ & + & 27 & Extensive & Open & * & 24 & 33 & \\
\hline 5 & 52 & $\mathrm{~F}$ & + & 15 & Grande & Open & * & 109 & 27 & \\
\hline 6 & 46 & $\mathrm{~F}$ & + & 36 & Large & Open & * & 104 & 23 & \\
\hline 7 & 48 & $\mathrm{~F}$ & + & 40 & Medium & Video & 2 & 57 & 13 & Adhesive capsulitis \\
\hline 8 & 52 & $M$ & & 18 & Extensive & Open & * & 74 & 12 & Torn again $^{1}$ \\
\hline 9 & 75 & $\mathrm{~F}$ & + & 2 & Extensive & Open & * & 36 & 30 & \\
\hline 10 & 61 & $M$ & + & 12 & Medium & Video & 1 & 24 & 35 & \\
\hline 11 & 33 & $M$ & + & 30 & Medium & Video & 2 & 24 & 34 & \\
\hline 12 & 51 & $M$ & + & 3 & Medium & Video & 2 & 24 & 35 & \\
\hline 13 & 47 & $\mathrm{M}$ & + & 96 & Medium & Video & 2 & 44 & 30 & \\
\hline 14 & 48 & $M$ & + & 25 & Medium & Video & 1 & 94 & 31 & \\
\hline 15 & 64 & $M$ & + & 230 & Extensive & Video & 4 & 24 & 34 & \\
\hline 16 & 63 & $\mathrm{~F}$ & & 4 & Large & Open & 2 & 24 & 14 & \\
\hline 17 & 43 & $M$ & + & 79 & Medium & Video & 4 & 24 & 35 & \\
\hline 18 & 46 & $\mathrm{~F}$ & + & 4 & Medium & Video & 2 & 27 & 34 & Torn again $^{2}$ \\
\hline 19 & 68 & $\mathrm{M}$ & + & 13 & Extensive & Video & 5 & 35 & 23 & Torn again $^{3}$ \\
\hline 20 & 61 & $M$ & + & 5 & Extensive & Open & * & 90 & 28 & \\
\hline 21 & 63 & $F$ & + & 5 & Extensive & Open & * & 72 & 14 & \\
\hline 22 & 66 & $\mathrm{~F}$ & + & 26 & Small & Video & 1 & 88 & 33 & Torn again ${ }^{4}$ \\
\hline 23 & 73 & $M$ & + & 28 & Extensive & Video & 5 & 60 & 34 & \\
\hline 24 & 58 & $M$ & & 6 & Small & Video & 2 & 66 & 34 & \\
\hline 25 & 59 & $M$ & & 9 & Medium & Video & 2 & 63 & 33 & \\
\hline 26 & 69 & $\mathrm{~F}$ & + & 9 & Small & Video & 1 & 24 & 34 & \\
\hline 27 & 61 & $\mathrm{~F}$ & + & 5 & Medium & Video & 1 & 80 & 34 & \\
\hline 28 & 60 & $M$ & & 1 & Large & Video & 1 & 63 & 30 & \\
\hline 29 & 76 & $F$ & + & 27 & Large & Video & 3 & 52 & 29 & \\
\hline 30 & 54 & $M$ & + & 10 & Extensive & Open & * & 99 & 29 & \\
\hline
\end{tabular}

Source: DOT-SCMSP

M: male; F: female; +: dominant side was affected; $\mathrm{N}^{\circ}$ : number

* Repairs performed using transosseous stitches

1 - Awaiting surgery (muscle transfer from latissimus dorsi)

2 - Two subsequent operations for repairs (one mini-open and one arthroscopic procedure)

3 - Dehiscence proven by magnetic resonance imaging. Patient did not want to undergo reoperation

4 - Third operation performed (arthroscopy) 
of the reoperation, according to the classification of Hawkins et $a l^{(13)}$, we found nine extensive lesions (30\%), six large lesions (20\%), 12 medium-sized lesions (40\%) and three small lesions (10\%). Associated procedures were performed in 16 cases $(53.3 \%)$ : acromioplasty in 14 cases; tenotomy on the tendon of the long head of the brachial biceps muscle in three cases, among which tenodesis was performed in one case; resection of the lateral extremity of the clavicle in six cases; and revision of this procedure in one case. The mean number of anchors installed, when used, was 2.2, with a range from one to five (Table 1).

During the postoperative period, the patients were immobilized using slings for six weeks, with release for free active exercises for the peripheral joints. After four weeks, passive lateral rotation was started (with a physiotherapist) and pendular movements without load-bearing. During the postoperative follow-up, the patients were reassessed using the criteria proposed by the University of California at Los Angeles (UCLA) ${ }^{(14)}$. The joint range of motion was measured in accordance with the criteria of the American Academy of Orthopaedic Surgeons (AAOS) ${ }^{(15)}$.

For the statistical analysis, we applied the MannWhitney test with the aim of investigating possible differences between the categories of the variables of sex, side affected, trauma, type of surgery (open or arthroscopic), treatment for lesions of the long head of the brachial biceps muscle and lesion size. We used the SPSS software (Statistical Package for Social Sciences), version 17.0, to obtain the results. We took the significance level to be 5\% (0.050) when applying the statistical tests.

\section{RESULTS}

The mean postoperative follow-up was 61 months, with a range from 24 to 152 months. Among the 30 patients who underwent a new surgical procedure, we found that the mean UCLA score was 28 , ranging from 12 to 35 . The results were considered to excellent in $36.7 \%$ of the cases; good in $33.3 \%$; fair in $13.3 \%$; and poor in $16.7 \%$ (Table 1).

The mean range of motion in the postoperative assessment was $133^{\circ}$ for elevation, ranging from $60^{\circ}$ to $150^{\circ} ; 51^{\circ}$ for external rotation, ranging from $30^{\circ}$ to $90^{\circ}$; and $\mathrm{T} 12^{\circ}$ for internal rotation, ranging from the gluteus to $\mathrm{T} 7$.
There were no statistically significant correlations for age, sex, presence of trauma in the first or second surgery and length of time with symptoms, in relation to the results and treatment for the brachial biceps $(p>$ 0.050). On the other hand, the size of the lesion, both in the initial surgery and in the second procedure, showed a statistically significant relationship $(p=0.049)$ with the results, given that among the nine cases with unsatisfactory results, the lesions were predominantly extensive or large, both in the first and in the second surgery (Tables 1 and 2).

Our study also showed that the results were predominantly unsatisfactory in the cases in which the access route was open. This was statistically significant in comparison with the operations performed using the open and arthroscopic routes $(p=0.001)$ (Table 2$)$. Out of these nine unsatisfactory cases, seven $(77.8 \%)$ underwent treatment via the open route in the second operation.

Complications were observed in five cases (16.7\%): one case that evolved with adhesive capsulitis and four with recurrence of symptoms (Table 1).

Table 2 - Clinical data on unsatisfactory results.

\begin{tabular}{c|c|c|c|c|c|c|c}
\hline Patient & Age & Sex & $\mathbf{1}^{\text {st }}$ size & $\mathbf{1}^{\text {st }}$ op & $\mathbf{2}^{\text {nd }}$ size & $\mathbf{2}^{\text {nd }}$ op & UCLA \\
\hline 1 & 55 & F & Extensive & Open & Medium & Open & 24 \\
\hline 3 & 70 & M & Large & Open & Large & Open & 15 \\
\hline 5 & 52 & F & Large & Open & Large & Open & 27 \\
\hline 6 & 46 & F & $*$ & Open & Large & Open & 23 \\
\hline 7 & 48 & F & Medium & Video & Medium & Video & 13 \\
\hline 8 & 52 & M & Extensive & Open & Extensive & Open & 12 \\
\hline 16 & 63 & F & Extensive & Video & Large & Open & 14 \\
\hline 19 & 68 & M & Extensive & Video & Extensive & Video & 23 \\
\hline \\
21 & 63 & F & $*$ & Open & Extensive & Open & 14 \\
\hline
\end{tabular}

\section{DISCUSSION}

Before thinking of repairing recurrences of rotator cuff lesions, it needs to be defined what constitutes a failure. Imaging examinations alone are not criteria for indicating a second surgical procedure ${ }^{(2,4,16)}$, since the lesion is not always compatible with the patient's functioning and complaints ${ }^{(17)}$. Using magnetic reso- 
nance examinations on asymptomatic volunteers, Sher et $a l^{(18)}$ showed that rotator cuff lesions could be found in individuals with good shoulder functioning and absence of symptoms. Thus, an anamnesis and complete physical examination are of paramount importance for diagnosing recurrences of these lesions.

The great majority of authors have shown in their studies that pain relief is achieved through the reoperation, although functional improvement is less likely to occur. Nonetheless, pain relief is the primary aim of the reoperation $^{(1,5,6,9,11)}$. In our study, $86.7 \%$ of the patients reported that they had achieved improvement of their pain, and $76.7 \%$ said that they had recovered a functional level similar to that of their contralateral limb, or only presented small limitations in the affected shoulder.

A variety of factors have been cited as causes of failure of the initial repair, thereby directly or indirectly compromising the functional result. These could also compromise the result from a second procedure if they continue to be present ${ }^{(2,6,9,19)}$. Among these factors, the following can be cited:

1) Inadequate subacromial decompression, which is one of the main causes of failure after the initial repair ${ }^{(2)}$. Among our sample, at the time of the second procedure, 14 patients (46.7\%) also underwent acromioplasty because they presented signs of impact;

2) Size of the lesion in the first repair: some studies have cited this as the most common cause of failure, with rates ranging from $67 \%$ to $97 \%$ in some series ${ }^{(5,12)}$. Studies have shown that patients who have small or medium-sized lesions at the time of the first procedure tend to evolve with better results from the reoperation than do those who initially presented large or extensive lesions ${ }^{(6,9,19)}$. In our sample, out of the nine patients with unsatisfactory results, six presented large or extensive lesions in the first procedure, while it was not possible to identify the size of the lesion in two cases, because they were operated at other services (Table 2).

3) Compromising of the deltoid muscle, which occurs in cases in which lateral or complete acromionectomy is performed, thereby modifying the lever arm of the deltoid muscle and resulting in difficulty in achieving elevation ${ }^{(2)}$. In assessing our unsatisfactory results, we saw that $66.7 \%$ underwent the first and second procedures via an open route. Two procedures using an open approach may compromise a greater number of fibers of the deltoid muscle, thus impairing the result;
4) Quality of the suture performed: in cases with loss of function in the presence of an adequate deltoid muscle, this leads towards envisaging that repair failure may have occurred ${ }^{(2)}$. Factors such as inadequate mobilization of the cuff, freeing of adherences, fatty degeneration of the tendon and inadequate fixation of the tendon to the bone or under tension are possible causes that might compromise the result from the repair, thus leading to recurrence of the lesion ${ }^{(2,6,9,19)}$. Three of our patients evolved with new tears after the reoperation (Table 1);

5) Inadequate rehabilitation: postoperative rehabilitation may compromise the procedure that has been carried out if it is not done correctly ${ }^{(2)}$. Delays in starting passive and active mobilization of the limb may progress to stiffness, thereby impairing the result, and this may also occur if mobilization and strength gain are started too early ${ }^{(2)}$. In our study, we did not identify any case in which the rehabilitation could be indicated as the cause of impaired results;

6) State of the long head of the brachial biceps muscle: it has been suggested in some studies that a non-functional biceps or a lesion in the biceps might contribute towards failure in the initial surgery because of the depressive effect of the humeral head, especially in large and extensive lesions. Thus, the use of tenotomy or tenodesis on these types of lesions is questionable ${ }^{(5,6)}$. In our sample, we did not find any relationship with unsatisfactory results, among the patients who underwent tenotomy or tenodesis of the long head of the biceps $(p \geq 0.05)$.

With regard to lesion size, the literature ${ }^{(16,20)}$ has demonstrated that recurrent lesions are smaller than the lesions treated initially. This was also seen in our study, given that out of the 17 patients whose first and second operations were both done in our service, eight cases presented smaller lesions than the initial ones, five cases had lesions of the same size and only four cases had lesions that were bigger than the primary lesions.

Regarding the route used in the second operation, the literature provides little information about cases treated arthroscopically ${ }^{(11)}$. Most of the published papers have reported that the open route was used ${ }^{(1,2,5,6,9,12,19)}$. Lo and Burkhart et al ${ }^{(\mathbf{1 1})}$ cited the following as advantages of performing the second procedure arthroscopically: a) it allows complete evaluation of the glenohumeral joint and the acromial space; b) there is minimal 
aggression to the deltoid muscle; c) it allows better viewing of the rotator cuff and the advantage of better mobilization of the lesion and viewing the tension in the repair and the edges of the repair, especially in lesions of U or L shape; d) lastly, arthroscopic surgery presents lower incidence of postoperative stiffness. In that study, the authors concluded that arthroscopic revision was a technically more difficult procedure, but that it might lead to improvement not only of pain but also of limb function. We agree with their conclusion: we had better results from arthroscopic surgery than from open repair of lesions $(p=0.001)$ (Figure 2).

\section{CONCLUSION}

Surgical treatment via open and arthroscopic routes to treat renewed tearing of the rotator cuff tends to present worse results than in the first operation. In the present study, we found that $70 \%$ of the results were excellent and good.

The presence of extensive lesions in the reoperation tends to evolve towards a greater number of unsatisfactory results $(p=0.049)$.

In our study, we obtained better results from surgery performed arthroscopically than from open surgery $(p=0.001)$.


Figure 2 - Same case as in Figure 1, showing a lateral view of the lesion in the tendon of the spinal supraspinatus muscle (A) and after suturing $(\mathrm{B})$.

\section{REFERENCES}

1. Bigliani LU, Cordasco FA, Mcllveen SJ, Musso ES. Operative treatment of failed repairs of the rotator cuff. J Bone Joint Surg Am. 1992;74(10):1505-15.

2. Neviaser RJ. Evaluation and management of failed rotator cuff repairs. Orthop Clin North Am. 1997;28(2):215-24.

3. Cummins CA, Murrell GA. Mode of failure for rotator cuff repair with suture anchors identified at revision surgery. J Shoulder Elbow Surg. 2003;12(2):12833.

4. Hanusch BC, Goodchild L, Finn P, Rangan A. Large and massive tears of the rotator cuff. Functional outcome and integrity of the repair after a mini-open procedure. J Bone Joint Surg Br. 2009;91(2):201-5.

5. Neviaser RJ, Neviaser TH. Reoperation for failed rotator cuff repair: Analysis of fifty cases. J Shoulder Elbow Surg. 1992;1(6):283-6.

6. Ma HL, Hung SC, Wang ST, Chen TH. The reoperation of failed rotator cuff repairs. J Chin Med Assoc. 2003;66(2):96-102.

7. Lichtenberg S, Liem D, Magosch P, Habermeyer P. Influence of tendon healing after arthroscopic rotator cuff repair on clinical outcome using single-row Mason-Allen suture technique: a prospective, MRI controlled study. Knee Sug Sports Traumatol Arthrosc. 2006;14(11):1200-6.

8. Goutallier D, Postel JM, Bernageau J, Lavau L, Voisin MC. Fatty muscle degeneration in cuff ruptures. Pre- and postoperative evaluation by CT scan. Clin Orthop Relat Res. 1994;(304):78-83.

9. Djurasovic M, Marra G, Arroyo JS, Pollock RG, Flatow EL, Bigliani LU. Revision rotator cuff repair: factors influencing results. J Bone Joint Surg Am. 2001;83(12):1849-55.

10. Checchia SL, Doneux PS, Miyazaki AN, Fregoneze M, Silva LA, Ishi M, et al. Avaliação dos resultados obtidos na reparação artroscópica das lesões do manguito rotador. Rev Bras Ortop. 2005;40(5):229-38.

11. Lo IK, Burkhart SS. Arthroscopic revision of failed rotator cuff repairs: technique and results. Arthroscopy. 2004;20(3):250-67.

12. DeOrio JK, Cofield RH. Results of a second attempt at surgical repair of failed initial rotator-cuff repair. J Bone Joint Surg Am. 1984;66(4):563-67.

13. Hawkins RJ, Misamore GW, Hobeika PE. Surgery for full-thickness rotator-cuff tears. J Bone Joint Surg Am. 1985;67(9):1349-55.

14. Ellman H, Kay SP. Arthroscopic subacromial descompression for chronic impingement. Two five years results. J Bone Joint Surg Br. 1991;73(3):395-98.

15. Hawkins RJ, Bokor DJ. Clinical evaluation of shoulder problems. In: Rocwood CA Jr, Matsen FA. The shoulder. Philadelphia: Saunders; 1998. p.175-80 .

16. Jost B, Pfirrmann CW, Gerber C. Clinical outcome after structural failure of rotator cuff repairs. J Bone Joint Surg Am. 2000;82(3):304-14.

17. Galatz LM, Ball CM, Teefey SA, Middleton WD, Yamaguchi K. The outcome and repair integrity of completely arthroscopically repaired large and massive rotator cuff tears. J Bone Joint Surg Am. 2004;86(2):219-24.

18. Sher J.S, Uribe J.W, Posado A. Abnormal findings on magnetic resonance images of asymptomatic shoulders. J Bone Joint Surg. 1995;77(A):10.

19. Jost B, Zumstein M, Pfirrmann CW, Gerber C. Long-term outcome after structural failure of rotator cuff repairs. J Bone Joint Surg Am. 2006;88(3):472-79.

20. Gerber C, Fuchs B, Hodler J. The results of repair of massive tears of the rotator cuff. J Bone Joint Surg Am. 2000;82(4):505-15. 